\title{
Analysis of 5 Floor Brick Masonry Building, Type 77/5
}

\section{Petraq Koka}

Lecturer at European University of Tirana

\begin{abstract}
Masonry structures represent one of the oldest building concepts available. Masonry construction is a traditional, widely used, extremely flexible, and economical construction method, with considerable potential for future developments. Masonry is a heterogeneous material, due to its composition of: Complete or perforated blocks; beds of continuous mortar; Nodes (joints) interrupted, or continuous.
\end{abstract}

Keywords: analysis, 5 floor brick, masonry building, type 77/5

\section{Introduction}

A masonry structure represents a behavior highly dependent on the reaction of the constituent elements: BRICK AND MORTAR. Brick had an elastic behavior in tensile and compressive, while the mortar doesn't behave like that. However, we can call it a homogeneous anisotropic material in terms of resistance and deformation. [Isai, C. (2009/10). Structural Design Course, Lecturer at the University of Trieste]

The study includes analyzes based on 2 steps:

Linear analysis, with the help of finite element model. (Etabs Program) *

Nonlinear analysis, performed with a simplified modeling procedure. (AM-Quake) ${ }^{1}$

\section{The main results of LINEAR ANALYSIS}

In the first steps of this analysis are identified the problems the building present, which are:

1- Displacement larger than allowed

2- Periods that exceed twice the recommended periods.

1- Displacement (with gray lines the deformed shape of the building is presented)

\footnotetext{
1 These 2 analyses have been published in other journals (EJERS and IJRAMR). For the purpose of this article we will refer below briefly "The main results of the linear analysis" only.
} 


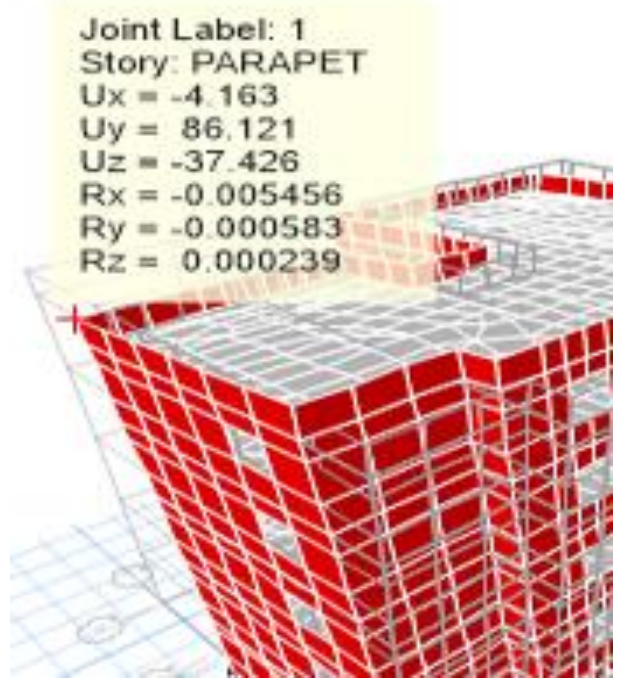

Fig. 3 - Displacements for the original building

Maximum displacement of the building, in the linear phase is $U y=8.61 \mathrm{~cm}>7.1 \mathrm{~cm}$, for the combination:

$$
\text { ELY: D + 0.3L + 0.3EQLX + EQLY }
$$

While in the nonlinear phase this displacement is:

$$
8.61 * \mathrm{q}=8.61 * 1.5=12.91 \mathrm{~cm}>>7.1 \mathrm{~cm}
$$

\section{2- Periods}

From the results of the modal analysis, for the combination ELY, the building manifests high periods in the first form of oscillation:

\section{Mode 1 - Period 0.688960526380029}

According to the recommendations of EC8, the period of self - oscillations, for masonry buildings, should be: $[\mathrm{T}]=0.05 \times \mathrm{Hg}{ }^{0.75}=0.05 \times 14.2^{0.75}=[0.366] \mathrm{sec}<<\mathrm{T}$ $=0.688 \mathrm{sec} ! ! !$

\section{Attempts and Recommendations for the Improvement of Displacements and Periods}

To improve the 2 main parameters of the building, the displacements and the periods, several hypothetical ATTEMPTS were performed, which assume that we have the 
opportunity to change the different physical masonry parameters. The realized attempts are given in the following:

\section{Attempt 1}

Based on the layered option provided by Etabs, it was assumed that we add outside masonry a $75 \mathrm{~mm}$ thick concrete cladding. A version with 2 "integration points" has been accepted.

The results of this attempt are:

- The displacements are: $U y=\mathbf{1 0 1 . 2 7} \mathrm{mm}$ and $\mathrm{Ux}=\mathbf{- 2 8 . 8} \mathrm{mm}$ !!

- The period in Mode 1 is $\mathbf{0 . 6 7 7} \mathrm{sec}$ :

\section{Mode 1 - Period 0.677413244630805}

The improvement is insignificant, the building continues to be flexible, the displacements in the plastic phase are $10.10 \mathrm{~cm} * 1.5$ (ductility) $=\mathbf{1 5 . 1 5} \mathrm{cm}$, while they should be $7.2 \mathrm{~cm}$ !!! The period increases, also the displacements, although this increase is insignificant. We emphasize that the change of the integration point parameter does not affect the period and displacements of the building.

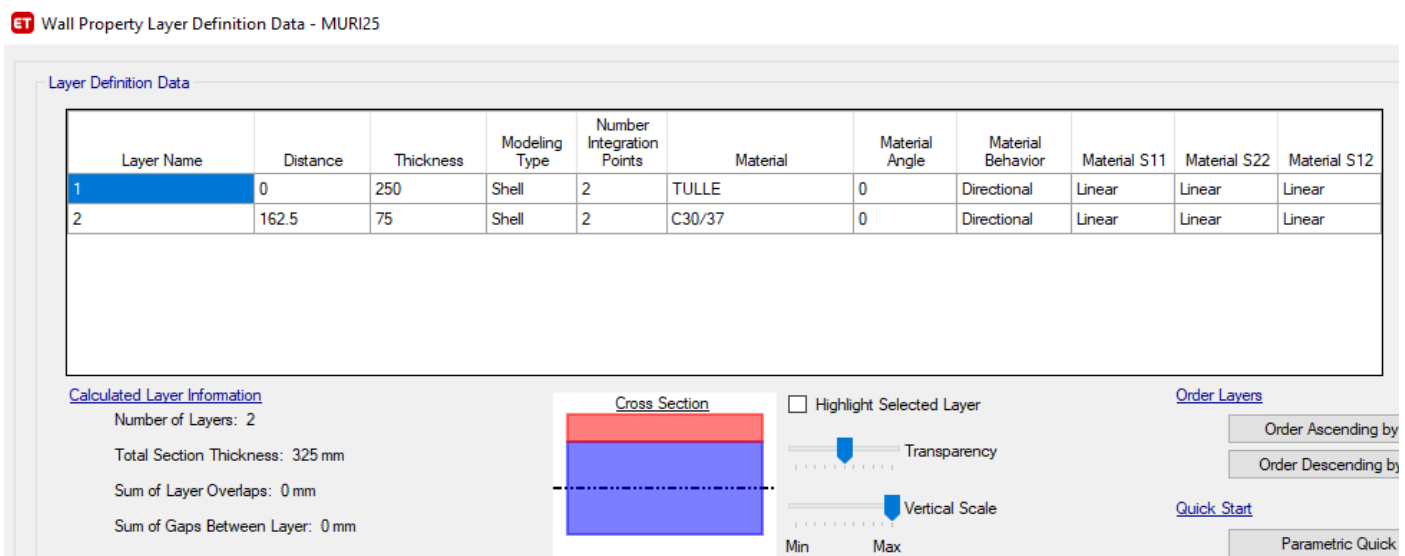

Fig. 4 - Wall layered data C30/37 


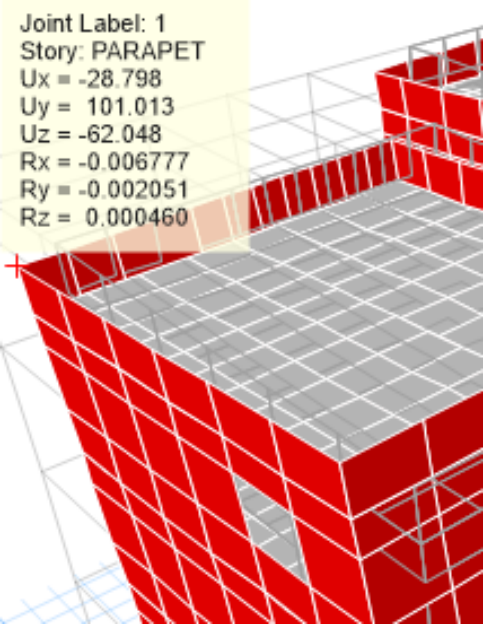

Fig. 5- Displacement at the top of the building for layered masonry.

\section{Attempt 2}

The same building is assumed to be built by concrete walls C30 / 37 .

It has the same plan, all built from concrete walls, with a thickness of $\mathbf{2 0} \mathbf{~ c m}$, except the brick partition walls, thick $12 \mathrm{~cm}$, the same as the original design. The results are:

- Displacement: Uy $=87.32 \mathrm{~mm}, \mathrm{Ux}=-27.56 \mathrm{~mm} !$

- Period in the first mode: $\mathrm{T}=0.613 \mathrm{sec}$

Improvements are insignificant, the change in displacements and periods for concrete structure is practically very small. That is, even the building is idealized with concrete elements, of high physical parameters, it's vulnerable again.

The replacement of the brick masonry with concrete, in this attempt, is realized to avoid any doubt regarding the idealization of brick masonry in "thin shell" elements, on ETABs, how they can be:

- A consequence of wrong acceptances on masonry parameters.

- Incorrect acceptance of masonry partition on shell elements.

Despite the fact that concrete has much higher physical characteristics than brick masonry, again the improvement on the above parameters, Periods and Displacement, are insensitive.

Several other attempts didn't give any target result. For shortening the article, I'm referring to them only one, that with the use of Fiber-Glasses. 


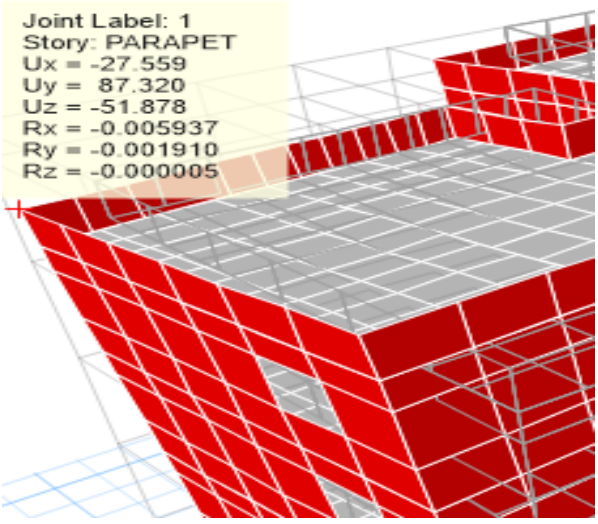

Fig. 6- Displacement at the top of the building in this attempt.

Attempt 3- The use of FIBER- GLLASES elements

The period for this case is $0.646 \mathrm{sec}$, the Uy displacement meet an insignificant decrease, it becomes $97.92 \mathrm{~mm}$

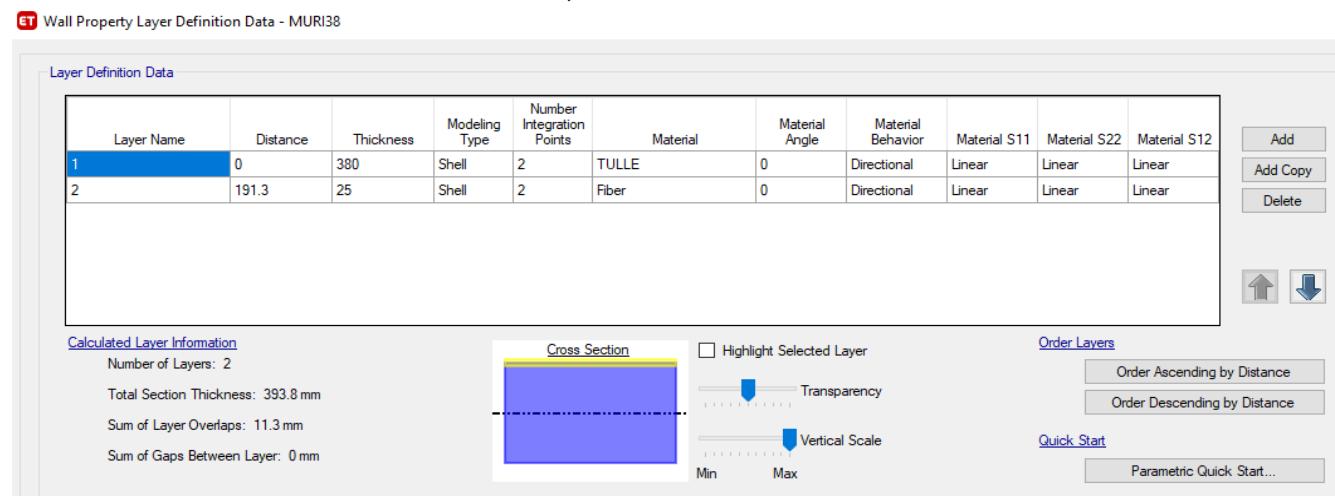

Fig. 7 - The fiber-glass layer on the outer wall of the masonry, for a wall of $25 \mathrm{~cm}$

\section{Key Features for Fiber- Glasses}

\begin{tabular}{|l|l|l|}
\hline QUALITIES & Standard ASTM & $22^{\circ} \mathrm{C}$ \\
\hline Elastic constants & & GPa \\
\hline
\end{tabular}




\begin{tabular}{|l|l|l|} 
Longitudinal module $\mathrm{E}_{\mathrm{L}}$ & $\mathrm{D} 3039$ & $53-59$ \\
\hline Transverse module $\mathrm{E}_{\mathrm{T}}$ & $\mathrm{D} 3039$ & $16-20$ \\
\hline Axial shearing module $\mathrm{G}_{\mathrm{LT}}$ & $\mathrm{D} 3518$ & $6-9$ \\
\hline Poisson's coefficient $\mathbf{m}_{\mathrm{LT}}$ & $\mathrm{D} 3039$ & $0.26-0.28$ \\
\hline Resistance & & MPa \\
\hline Longitudinal traction $\mathrm{F}_{\mathrm{L}}$ & $\mathrm{D} 3039$ & $1590-$ \\
\hline Longitudinal pressure $\mathrm{FC}_{\mathrm{C}}$ & $\mathrm{D} 3410$ & 6900 \\
\hline Transverse traction $\mathrm{FT}_{\mathrm{T}}$ & $\mathrm{D} 3039$ & $41-82$ \\
\hline Transverse pressure $\mathrm{FCH}_{\mathrm{T}}$ & $\mathrm{D} 3410$ & $110-200$ \\
\hline
\end{tabular}

In my opinion, reinforcement with FRP, in addition to the insignificant change of parameters, has high economic costs, for many reasons, which are not subject to this treaty.

Attempt 4: COLUMNS only on the first 2 floors

This is also the last attempt, which gave a satisfactory result.

In this attempt, finally, the Periods and Displacements have met the intended Target

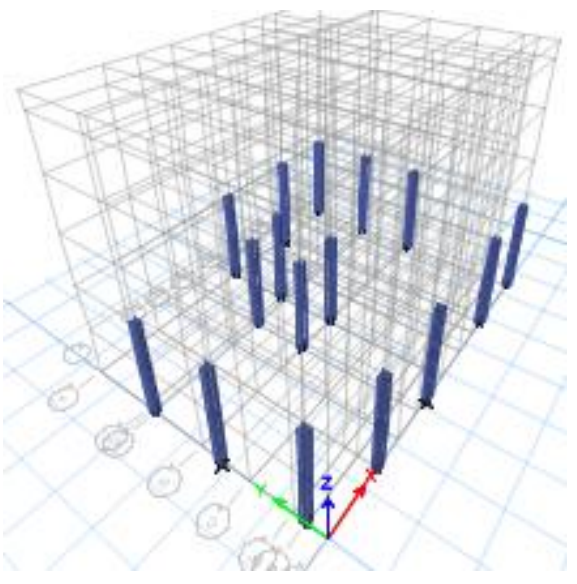

Fig 8- Columns in 2 floors

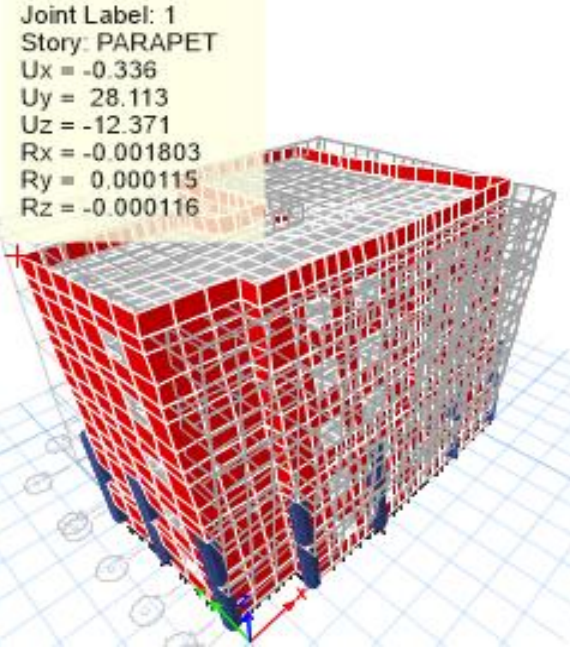

Fig 9- Displacement for ELY combination 

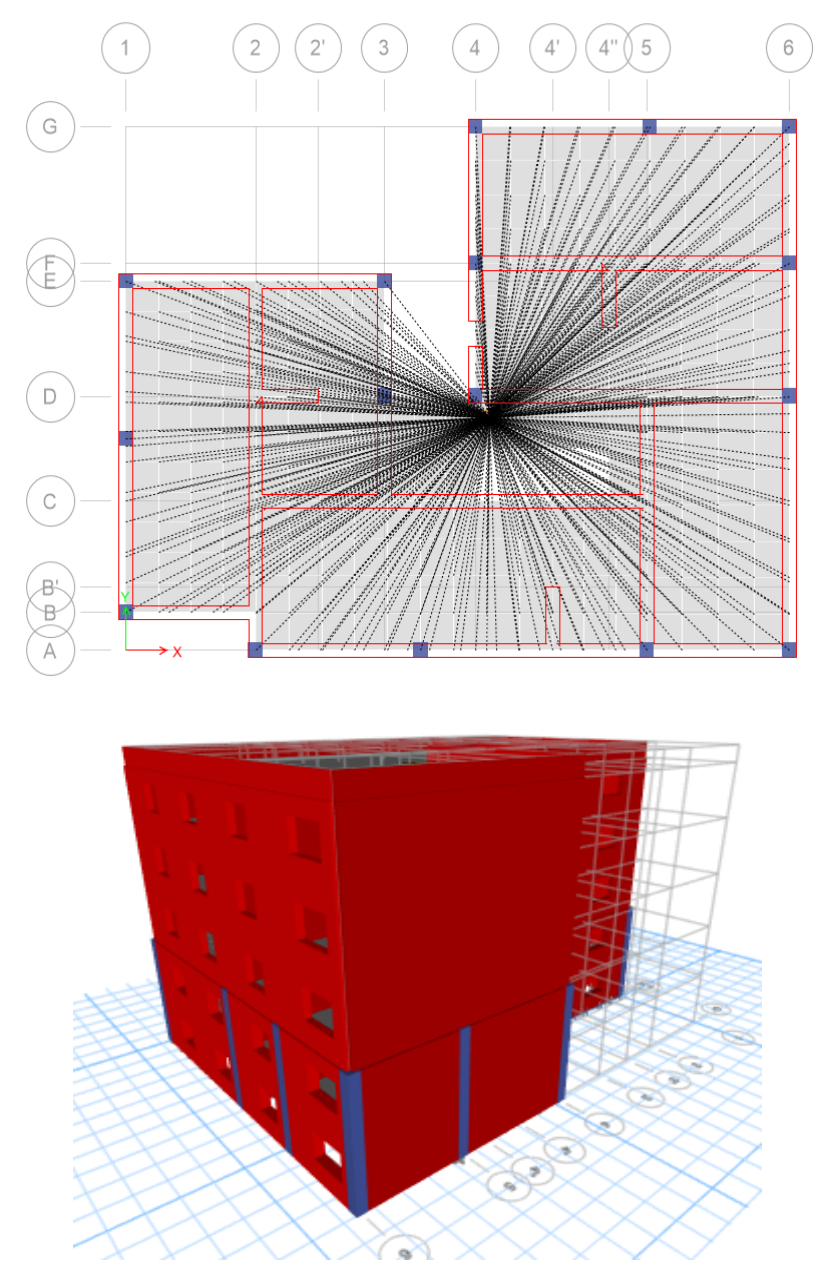

Fig.10 - The column position, in plan and in 3D.

a- $\quad$ The period in the first modal form was reduced to the value:

$$
\text { Mode } 1 \text { - Period } 0.352056254329364
$$

Remind that the allowed period per building is

$$
[\mathrm{T}]=\mathbf{0 . 3 6 5} \mathrm{sec}
$$

b- The maximum displacements for the ELY combination are reduced to the value:

$\mathrm{Uy}=28.13 \mathrm{~mm}$

In the plastic phase, these displacements will be: 


\section{$28.13 * 1.5=42.19 \mathrm{~mm}$}

They are now much smaller than the allowable displacements, $[\mathrm{Ux}]$ and $[\mathrm{Uy}]=7.1 \mathrm{~cm}$ Practically, the above results are very important for the following reasons:

1. Finally, we have a solution according to which the building has the displacements and periods within the recommendations of the Eurocode, consequently in case of an earthquake, the lives of the people lodging on them, are not endangered.

2. Is the most possible economical solution, it relies on the use of traditional construction materials, such as concrete and steel, especially when a relatively large number of buildings needs to be reinforced, in a country with limited economic opportunities, such as Albania.

3. Improves stresses in the wall panels. [ they are not cited in this article].

4. The columns are all located in the perimeter, where their realization is more likely to be carried out even in conditions when people live within the dwellings they own.

\section{Conclusion}

The study of this building started a long time before 26.11.2019 when Albania was affected by an earthquake of 6.3 Richter magnitude, which caused over 50 victims and a lot of material damage. One of the buildings affected by this earthquake was this kind of building. Therefore, the study and the exact results for the way of improvement of this building is an important task not only of this study but also of other studies that will be undertaken in the future, by other colleagues, in the following.

I think that an important factor in the fact that the periods of this building are high, for the version of brick masonry 25 and $38 \mathrm{~cm}$, or in the version with the layered wall, is the own weight of the masonry!

\section{Literature}

[1] Agy, High Strength Glass Fibers, World Headquarters/Americas, Pub. No. LIT-2006$111 \mathrm{R} 2(02 / 06)]$

[2] Albania Academy of Sciences, KTP-N.2-89. Technical Design Conditions, 1989.

[3] Alberto Antonellia, Michele Bettia, Maria Luisa Del Saviob, Luciano Galanoa, Maurizio Orlandoa. "Methods for Seismic Analysis of Existing Masonry Buildings"2010.

[4] B. Furiozzi,C. Messina, L. Paolini, Manual for the Calculation of Structural Elements, New Edition, 2007.

[5] Calvi G. M., Kingsley G. R., Magenes G., 1996: " Masonry Structures Testing, for Seismic Assessment ". Earthquake Spectrum, Vol. 12, No. 1

[6] Central Archive of the Ministry of Construction, Tirana.

[7] ETABS@ Version 18.1.1 2020, (C) Computers and Structure, Inc. 
[8] Eurocode EC6, EC8.

[9] Isai Clemente, Structural Design Course, Lecturer at the University of Trieste, $2009 / 10$

[10] Kerstin Lang, Seismic Vulnerability of Existing Buildings, Zurich Institute of Structural Engineering, Swiss Federal Institute of Technology, February 2002.

[11] Markel Baballëku, Structural Damage Assessment in Education System Buildings, Tirana, November 2014. 